\title{
Turn up the pump or fix the leak?
}

\author{
Mark Helmers, MD, and Pavan Atluri, MD
}

\author{
From the Division of Cardiovascular Surgery, Department of Surgery, University of Pennsylvania, Philadelphia, \\ $\mathrm{Pa}$. \\ Disclosures: Authors have nothing to disclose with regard to commercial support. \\ Received for publication April 28, 2017; accepted for publication May 11, 2017; available ahead of print July 22, \\ 2017. \\ Address for reprints: Pavan Atluri, MD, Division of Cardiovascular Surgery, Hospital of the University of Penn- \\ sylvania, 3400 Spruce St, 6 Silverstein Pavilion, Philadelphia, PA (E-mail: Pavan.Atluri@uphs.upenn.edu). \\ J Thorac Cardiovasc Surg 2017;154:1313-4 \\ $0022-5223 / \$ 36.00$ \\ Copyright (C) 2017 by The American Association for Thoracic Surgery \\ http://dx.doi.org/10.1016/j.jtcvs.2017.05.023
}

Mitral regurgitation (MR) is the most common valvular pathology in patients with advanced congestive heart failure. ${ }^{1}$ The majority of this MR is functional, a result of the ventricular dilation and spherical remodeling associated with heart failure. Ventricular decompression with left ventricular assist devices (LVADs) increases mitral leaflet coaptation and often abates MR. Long term, as the ventricle remodels, the displacement of the papillary muscles may improve, thereby minimizing the malcoaptation of the valve. In one series, LVAD implantation decreased the prevalence of moderate or severe MR from $77 \%$ before implantation to $11 \%$ at 6 months after implantation. ${ }^{2}$ Furthermore, similar 1-year survivals have been reported in LVAD recipients with and without persistent MR after device placement. ${ }^{3}$ As such, current guidelines do not recommend mitral valve intervention for severe MR at the time of LVAD implantation unless ventricular recovery is expected. ${ }^{4}$ The utility of concomitant mitral valve intervention remains, however, a hotly debated topic without consensus.

In this issue of the Journal, Fukuhara and colleagues ${ }^{5}$ present retrospective data that challenge the current paradigm. Of 115 LVAD recipients with greater than moderate preexisting MR, $63(54.8 \%)$ went without mitral valve repair and the other $52(45.2 \%)$ underwent concomitant mitral valve repair consisting of either annuloplasty or edge-toedge repair (Alfieri stitch). As expected, the mitral valve repair group had longer cardiopulmonary bypass times; however, there were no differences between the groups in early postoperative complications, blood product use, or dosage of vasoactive drugs. MR was durably controlled by either annuloplasty or edge-to-edge repair at 2 years after LVAD implantation, whereas approximately $30 \%$ of the patients in the nonrepair group had significant MR.

Although there was no difference between groups in right heart failure (RHF) during the index admission, patients in the mitral valve repair group were less likely to have late RHF develop (2.2\% vs $13.6 \%)$. Fukuhara and colleagues ${ }^{5}$ postulate that this effect may be due in part to the lower pump speeds allowed by mitral valve repair. Pump speed is typically adjusted to optimize left ventricular unloading,

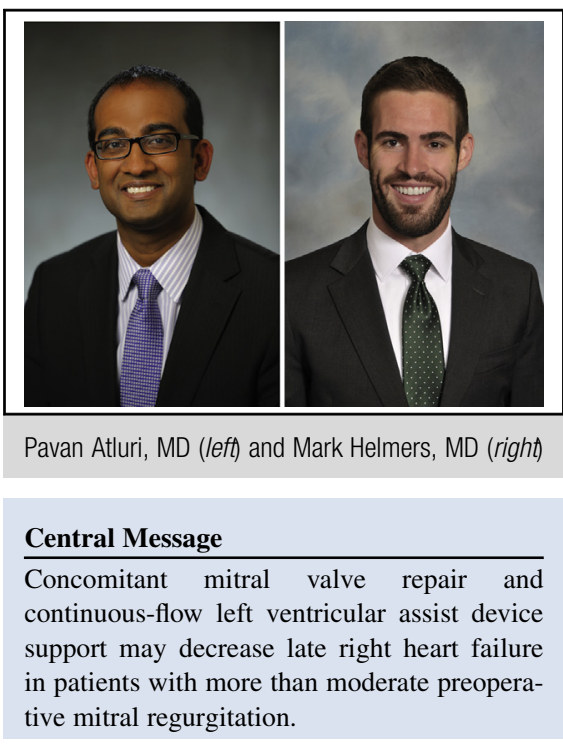

See Article page 1303.

interventricular septal position, aortic valve opening, and MR. ${ }^{6}$ MR can be mitigated by increasing pump speed; however, this increase may predispose patients toward the development of RHF by increasing the preload of the right ventricle and deleteriously affecting right ventricular geometry and contractile efficiency through septal bowing. ${ }^{7,8}$ Indeed, mean predischarge pump speeds were significantly lower in patients who had the HeartMate II (Thoratec Corporation, Pleasanton, Calif) implanted and also underwent mitral valve repair than in recipients who had no concomitant mitral intervention (8931 rpm vs $9200 \mathrm{rpm})$.

As has been repeatedly demonstrated, the development of late RHF may portend dismal outcomes. Of the 9 patients in the study who had late RHF develop, 6 were bridged to transplant. Notably, the 2-year posttransplant survival was only $33.3 \%$ in this group, as opposed to a survival of $93.3 \%$ in the 45 patients who received transplants but did not have late RHF develop.

Given its retrospective nature, this study is subject to confounding and certain biases, including selection bias. Although none of the potential confounders demonstrated association with late RHF in a multivariate regression, the patients in the mitral valve repair group were more recent in the study period and were more likely to be receiving the LVAD as destination therapy. Regardless of these limitations, Fukuhara and colleagues ${ }^{5}$ should be commended for their contribution. Their work certainly challenges the 
theory that concomitant and mitral valve repair is unnecessary with continuous-flow LVAD implantation, and it suggests that further investigation is warranted.

\section{References}

1. Patel JB, Borgeson DD, Barnes ME, Rihal CS, Daly RC, Redfield MM. Mitral regurgitation in patients with advanced systolic heart failure. J Card Fail. 2004; 10:285-91.

2. Morgan JA, Brewer RJ, Nemeh HW, Murthy R, Williams CT, Lanfear DE, et al. Left ventricular reverse remodeling with a continuous flow left ventricular assist device measured by left ventricular end-diastolic dimensions and severity of mitral regurgitation. ASAIO J. 2012;58:574-7.

3. Kitada S, Kato TS, Thomas SS, Conwell SD, Russo C, Di Tullio MR, et al. Pre-operative echocardiographic features associated with persistent mitral regurgitation after left ventricular assist device implantation. J Heart Lung Transplant. 2013;32:897-904.
4. Kirklin JK, Naftel DC, Pagani FD, Kormos RL, Stevenson LW, Blume ED, et al. Seventh INTERMACS annual report: 15,000 patients and counting. J Heart Lung Transplant. 2015;34:1495-504.

5. Fukuhara S, Takeda K, Chiuzan C, Han J, Kurlansky PA, Takayama H, et al. Concomitant mitral repair and continuous-flow left ventricular assist devices: is it warranted? J Thorac Cardiovasc Surg. 2017;154:1303-12.e4.

6. Uriel N, Morrison KA, Garan AR, Kato TS, Yuzefpolskaya M, Latif F, et al. Development of a novel echocardiography ramp test for speed optimization and diagnosis of device thrombosis in continuous-flow left ventricular assist devices: the Columbia ramp study. J Am Coll Cardiol. 2012;60:1764-75.

7. Tanaka A, Onsager D, Song T, Cozadd D, Kim G, Sarswat N, et al. Surgically corrected mitral regurgitation during left ventricular assist device implantation is associated with low recurrence rate and improved midterm survival. Ann Thorac Surg. 2016;103:725-33.

8. Neragi-Miandoab S, Goldstein D, Bello R, Michler R, D’Alessandro D. Right ventricular dysfunction following continuous flow left ventricular assist device placement in 51 patients: predicators and outcomes. J Cardiothorac Surg. 2012;7:60. 